\title{
ROLE OF PLEURAL FLUID CHOLESTEROL IN DIFFERENTIATING TRANSUDATIVE AND EXUDATIVE PLEURAL EFFUSION
}

\author{
Tariq Mahmood ${ }^{1}$, Kaleem Ahmad ${ }^{2}$, Arvind Kumar Verma ${ }^{3}$, A. D. Shukla ${ }^{4}$, Abhinav C5, Srinivasa ${ }^{6}$ \\ 1 Professor and Head, Department of Pulmonary Medicine, MLN Medical College, Allahabad, U. P. \\ ${ }^{2} 3^{\text {rd }}$ Year Junior Resident, Department of Pulmonary Medicine, MLN Medical College, Allahabad, U. P. \\ 33rd Year Junior Resident, Department of Pulmonary Medicine, MLN Medical College, Allahabad, U. P. \\ ${ }^{4}$ Associate Professor, Department of Pulmonary Medicine, MLN Medical College, Allahabad, U. P. \\ ${ }^{5}$ Senior Resident, Department of Pulmonary Medicine, SGPGI, Lucknow. \\ ${ }^{6}$ Senior Resident, Department of Pulmonary Medicine, KMC, Mangalore.
}

\begin{abstract}
BACKGROUND
ABSTRACT

Pleural effusion is defined as an abnormal and excessive collection of fluid in the pleural space. The most common cause in the West and India are infections followed by malignancy. In India, tubercular effusion is the most common cause followed by malignant effusion and a very few due to parapneumonic effusion.

Aims and Objectives- To study the role of pleural fluid cholesterol in differentiating transudative and exudative pleural effusion and comparison of pleural fluid cholesterol to Light's criteria.
\end{abstract}

\section{MATERIALS AND METHODS}

In this prospective study, 204 patients with pleural effusion were included. Pleural fluid cholesterol, total protein, lactate dehydrogenase (LDH) as well as serum total protein and LDH levels along with other required investigations were studied. Clinical classification of transudative or exudative was done on the basis of aetiology.

\section{RESULTS}

Based on pleural fluid examination for cholesterol, protein, LDH and other haematological investigations and response to treatment besides history, clinical examination finding and chest radiograph, 173 patients were classified as exudates and 31 as transudates. Using pleural fluid cholesterol levels at a cut-off point of greater than $45 \mathrm{mg} / \mathrm{dL}$ for distinguishing transudates and exudates the sensitivity, specificity, positive predictive value (PPV) and negative predictive value (NPV) were 98\%, 100\%, 98\% and $100 \%$ respectively. In the present study when pleural fluid cholesterol cut-off was taken as $60 \mathrm{mg} / \mathrm{dL}$ it was found that the sensitivity of differentiating exudates was $82 \%$, while specificity was found to be $100 \%$ with PPV of $100 \%$ and NPV of $44 \%$. Using Light's criteria for discriminating transudates and exudates, sensitivity, specificity, PPV and NPV were found to be $98 \%, 100 \%$, $100 \%$ and $92 \%$ respectively. In the present study, pleural fluid protein $>3 \mathrm{gm} / \mathrm{dL}$ when used as a differentiating parameter for transudates and exudates had a sensitivity of $98 \%$, specificity and PPV of $100 \%$ and NPV of $74 \%$ respectively.

\section{CONCLUSION}

Pleural fluid cholesterol is cost-effective and useful parameters in distinguishing transudative from exudative aetiologies with the advantage of requiring only one laboratory determinations and no simultaneous blood sample compared to the use of Light's criteria.

\section{KEYWORDS}

Pleural Fluid Cholesterol, Transudative, Exudative, Light's Criteria.

HOW TO CITE THIS ARTICLE: Mahmood T, Ahmad K, Verma AK, et al. Role of pleural fluid cholesterol in differentiating transudative and exudative pleural effusion. J. Evolution Med. Dent. Sci. 2018;7(07):909-913, DOI: 10.14260/jemds/2018/207

\section{BACKGROUND \\ Pleural effusion is defined as an abnormal collection of fluid} in the pleural space. Two types of effusions can develop (transudative and exudative). Transudative pleural effusions are caused by fluid leaking into the pleural space and increased hydrostatic pressure or decreased osmotic pressure. Exudative effusions are caused by blocked blood

'Financial or Other Competing Interest': None.

Submission 27-12-2017, Peer Review 26-01-2018,

Acceptance 01-02-2018, Published 12-02-2018.

Corresponding Author:

Dr. Tariq Mahmood,

Professor and Head,

Department of Pulmonary Medicine,

MLN Medical College,

Allahabad-211001, Uttar Pradesh, India.

E-mail: mlnmctariqmahmood@gmail.com

DOI: $10.14260 /$ jemds/2018/207

\section{(c) (i) $(9)$}

vessels, inflammation, lung injury and drug reactions which causes damage or disruption of pleural membranes or vasculature (Bartter et al, 1994).

The most common cause in the West are infections followed by malignancy, 1 while in India it is tubercular effusion followed by malignant effusion ${ }^{2}$ and a very few due to parapneumonic effusion.

Exudative pleural effusions are a common diagnostic problem in clinical practice as the list of causes is quite exhaustive, ${ }^{1}$ although sometimes they can be inferred from the clinical picture. The aetiological distribution of pleural effusions in various series depends on the geographical area, patient's age and advances in the diagnostic methods and treatment of the underlying causes. The difficulty in determining the cause of pleural effusion is shown by the fact that in many series "unknown aetiology" constitutes nearly $15 \% .^{3}$ Exudative effusions require to be separated into infectious causes, non-infectious causes and malignancy. 


\section{Aims and Objectives}

- To study the diagnostic value of pleural fluid cholesterol in differentiating transudative and exudative pleural effusion.

- To compare pleural fluid cholesterol level for exudates with Light's criteria.

- To evaluate the usefulness of diverse combinations of pleural cholesterol concentration, pleural or serum protein and lactate dehydrogenase (LDH) levels for the differentiation of pleural exudates and transudates.

\section{MATERIALS AND METHODS}

This study was conducted in the Department of Pulmonary Medicine, MLN Medical College, Allahabad, over a period of 1 year from June 2016 to July 2017. All patients of either sex with pleural effusions were enrolled in this study as per inclusion and exclusion criteria. This was an observational cross-sectional study.

A total of 204 patients (153 males and 51 females) with clinical diagnosis of pleural effusion were enrolled for study. Among 204 patients 173 patients were diagnosed as exudative pleural effusion (tubercular, para-pneumonic and malignancy), while 31 patients were cases of Transudative pleural effusion (Congestive heart failure, Chronic liver disease etc.).

All patients qualifying for inclusion criteria were explained in detail about the study and procedures involved and informed consent was taken. A detailed history was taken about symptoms such as cough, expectoration, breathlessness, fever, weight loss, haemoptysis and chest pain. Clinical examination and necessary investigations were done including chest radiograph postero-anterior view, sputum acid-fast bacilli stain, USG thorax, pleural fluid aspiration, and analysis for protein, sugar, LDH, cholesterol, ADA, cell count and required blood investigations. The statistical analysis was performed using Microsoft Excel. The sensitivities, specificities, positive predictive values and negative predictive values were obtained. The aetiological classification according to the criteria of Light et $\mathrm{al}^{4}$ was used as the "Gold Standard."

\section{RESULTS}

A total of 204 patients (153 males and 51 females) with clinical diagnosis of pleural effusion were enrolled for study. Among 204 patients 173 patients were diagnosed as exudative pleural effusion (tubercular, para-pneumonic and malignancy), while 31 patients were cased of transudative pleural effusion (Congestive heart failure, Chronic liver disease etc.).

Study was carried out in a time duration of June 2016 to July 2017. The commonest type of effusion was found to be Tuberculous (158 cases) followed by Congestive heart failure (21 cases), Malignancy (11 cases), Para-pneumonic (4 cases), Chronic liver disease (5 cases), Rheumatic heart disease (4 cases) and one case of Nephrotic syndrome was identified as shown in Table 1. The most frequent cause of pleural exudates is tuberculosis followed by lung cancer, which is similar to the result of a study done in high tuberculosis burden countries.

\begin{tabular}{|c|c|c|}
\hline Diagnosis & Transudate & Exudate \\
\hline Tuberculosis & $\mathbf{5}$ & $\mathbf{1 5 3}$ \\
\hline Congestive heart failure & $\mathbf{1 3}$ & $\mathbf{8}$ \\
\hline Malignancy & $\mathbf{1}$ & $\mathbf{1 0}$ \\
\hline Chronic liver disease & $\mathbf{5}$ & \\
\hline Para-pneumonic effusion & & $\mathbf{5}$ \\
\hline Nephrotic syndrome & $\mathbf{1}$ & \\
\hline Rheumatic heart disease & $\mathbf{4}$ & \\
\hline
\end{tabular}

Table 1. Clinical Diagnosis of Patient Presented with Pleural Effusion according to Light's Criteria

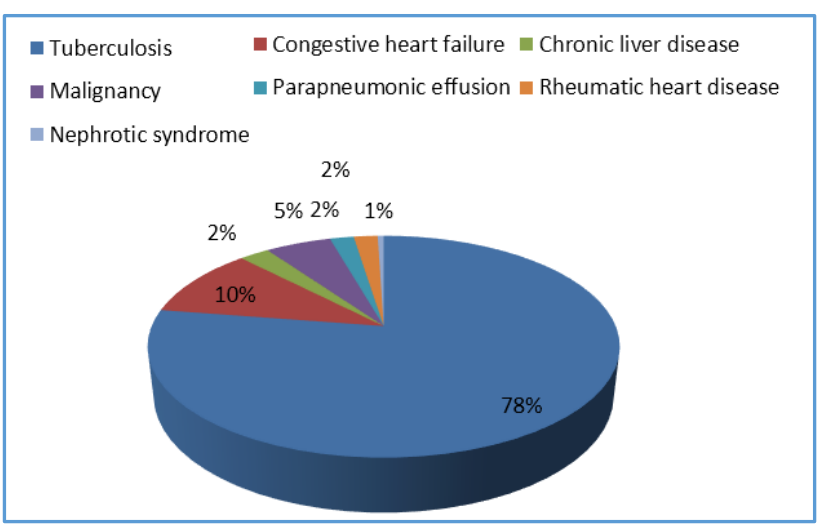

\section{Percentage Distribution of Disease}

176 (84\%) were exudates and $28(16 \%)$ cases were transudates according to Light's criteria. ${ }^{4}$ (Pleural fluid protein/ serum protein ratio greater than 0.5 , pleural fluid $\mathrm{LDH} /$ serum LDH ratio greater than 0.6, pleural fluid LDH level greater than two-thirds the upper limit of the laboratory's reference range of serum LDH). It was found that the sensitivity and specificity of separating transudate and exudates with light's criteria is $98 \%$ and $100 \%$ respectively.

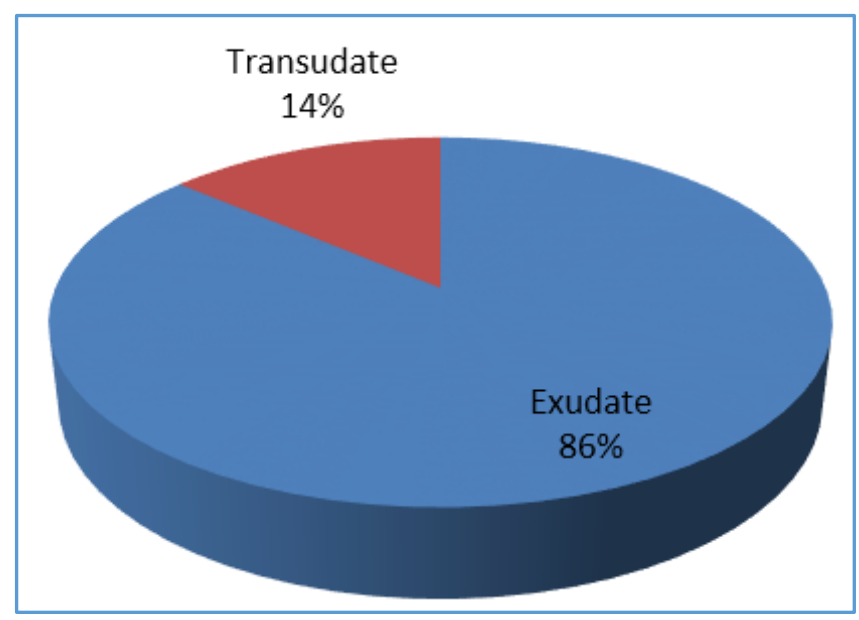

Percentage Distribution of Exudates and Transudates

Out of total 204 patients, 173 had pleural fluid cholesterol level greater than $45 \mathrm{mg} / \mathrm{dL}$ with sensitivity $98 \%$ and specificity $100 \%$, and 135 patients had cholesterol level greater than 60 $\mathrm{mg} / \mathrm{dL}$ with sensitivity of $82 \%$ and specificity of $100 \%$. When pleural fluid cholesterol alone was used at a cut-off point of 45 $\mathrm{mg} / \mathrm{dL}, 3$ out of the 176 (as compared to Light's criteria) was misclassified as transudate (sensitivity 98\%), while there was no misclassification of 28 transudates (specificity $100 \%$ ). 
When pleural fluid cholesterol with a cut-off point of greater than $60 \mathrm{mg} / \mathrm{dL}$ was used as criteria for exudates, 31 out of 176 patients were misclassified as transudative pleural effusion, (sensitivity 82\%) and 135 patients had exudative pleural effusion, while there is no misclassification of transudative pleural effusion with specificity of $100 \%$.

The mean value of pleural fluid cholesterol in tuberculous, malignant and transudative pleural effusion was found to be $82.7,66.6$ and 27.3 respectively.

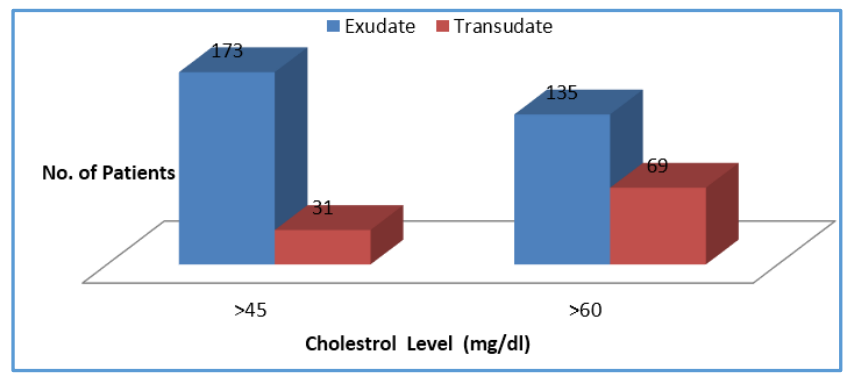

Comparison of Cholesterol Cut-Off Criteria

When pleural fluid protein and serum protein ratio $>0.5$ alone was used as a criterion, 156 out of 204 patients classified had exudative pleural effusion with sensitivity of $81 \%$ and specificity of $100 \%$. Pleural fluid LDH and serum LDH ratio $>0.6$ alone classified 177 exudate out of 204 patients with specificity of $88 \%$ and sensitivity of $100 \%$.

\begin{tabular}{|c|c|c|c|c|}
\hline Parameters & \begin{tabular}{|c|} 
Sensitivity \\
$\%$
\end{tabular} & $\begin{array}{c}\text { Specificity } \\
\%\end{array}$ & $\begin{array}{c}\text { PPV } \\
\%\end{array}$ & $\begin{array}{c}\text { NPV } \\
\%\end{array}$ \\
\hline $\begin{array}{c}\text { Pleural fluid } \\
\text { Cholesterol Cut-off } \\
>45 \mathrm{mg} / \mathrm{dL}\end{array}$ & 98 & 100 & 98 & 100 \\
\hline $\begin{array}{l}\text { Pleural fluid } \\
\text { Cholesterol Cut-off } \\
>60 \mathrm{mg} / \mathrm{dL} \\
\end{array}$ & 82 & 100 & 100 & 44 \\
\hline $\begin{array}{l}\text { Pleural fluid } \\
\text { Protein/serum } \\
\text { protein }>0.5\end{array}$ & 81 & 100 & 100 & 44 \\
\hline $\begin{array}{l}\text { Pleural fluid LDH } \\
\text { Serum LDH > } 0.6\end{array}$ & 100 & 88 & 97 & 100 \\
\hline Light's criteria & 98 & 100 & 100 & 91 \\
\hline $\begin{array}{l}\text { Pleural fluid LDH > } \\
2 / 3 \text { UL of } \\
\text { Serum LDH } \\
\end{array}$ & 82 & 100 & 100 & 46 \\
\hline $\begin{array}{c}\text { Pleural fluid protein } \\
>3 \mathrm{gm} / \mathrm{dL}\end{array}$ & 94 & 100 & 100 & 74 \\
\hline \multicolumn{5}{|c|}{$\begin{array}{c}\text { Table 2. Shows Sensitivity, Specificity, Positive Predictive } \\
\text { Value (PPV) and Negative Predictive Value (NPV) of } \\
\text { various Laboratory Parameters for Transudates and } \\
\text { Exudates Separation }\end{array}$} \\
\hline
\end{tabular}

In this study when pleural fluid protein $\geq 3 \mathrm{gm} / \mathrm{dL}$ was used to separating transudates and exudates 158 patients had exudative pleural effusion, while 46 patients were identified as having transudative pleural effusion with sensitivity $94 \%$, specificity $100 \%$, positive predictive value $100 \%$ and negative predictive value of $74 \%$.

When pleural fluid LDH $>2 / 3$ of upper limit of serum LDH used as parameters it has $82 \%$ sensitivity, $100 \%$ specificity positive predictive value of $100 \%$ and negative predictive value of $46 \%$.
On Pearson correlation test pleural fluid cholesterol correlation is 1 and on the basis of protein ratio this is 0.9 . This suggests that pleural fluid cholesterol is highly correlated than protein ratio with clinical diagnosis for exudates for level of significance at the level of $\alpha=0.01$.

For level of significance $(\alpha=0.05)$, for pleural fluid cholesterol $>45 \mathrm{mg} / \mathrm{dL}$ and pleural fluid cholesterol $>60 \mathrm{mg} / \mathrm{dL}$, $p=0.08$ which is greater than level of significance $(\alpha=0.05)$. This shows that there is no significance between these two cutoff criteria.

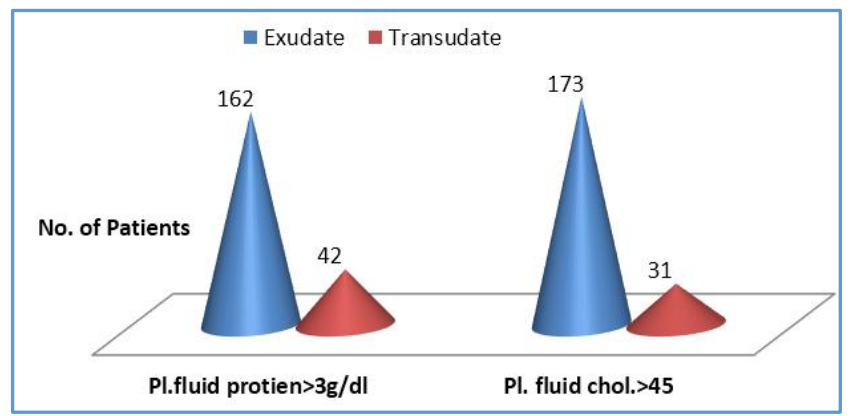

Transudate and Exudate on Basis of Protein and Cholesterol Criteria

\begin{tabular}{|c|c|c|}
\hline Studies & Tuberculous & Non-Tuberculous \\
\hline SK Sharma et $\mathrm{al}^{5}$ & 95.8 & 30.7 \\
\hline PK Sinha et $\mathrm{al}^{6}$ & 76.8 & 14.5 \\
\hline $\begin{array}{c}\text { Dharmendra A } \\
\text { Bamaniya et al }\end{array}$ & 65.48 & 24.29 \\
\hline Present Study & 62.33 & 24.33 \\
\hline Table 3. Mean Values of ADA in Tuberculous and Non- \\
Tuberculous Pleural Effusion
\end{tabular}

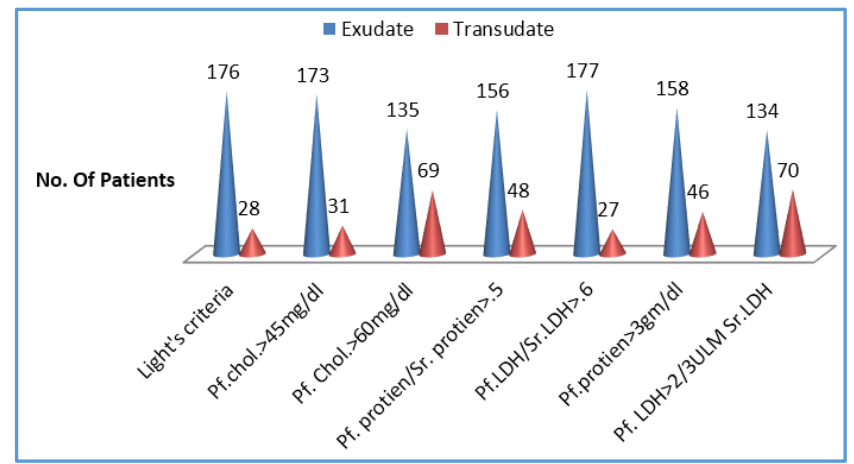

Number of Transudate and Exudate on basis of Different Parameters

\section{DISCUSSION}

Pleural effusion is commonly encountered condition in clinical practice. The initial step in the management of pleural effusions is to distinguish transudates from exudates. Various biochemical tests have been used in diagnosis of pleural effusion. This study has evaluated the diagnostic value of different biochemical tests used for evaluation of pleural fluid.

The criteria often used to do so are based on biochemical parameters proposed by Light et al. ${ }^{4}$ Since no single test has yet proved to be completely satisfactory, the search for improved methods continues.

In the present study, majority of pleural effusions were of exudative nature (86\%). As the most of cardiac, renal and 
liver disease patients first approach the Internal Medicine Department of hospital, most of the transudative effusions were managed further by Medicine Department, so the number of transudative effusions managed in Pulmonary Medicine Department of the hospital were relatively less. In this study, tubercular pleural effusion was found in $78 \%$ of patients.

Table 2 shows comparison of different studies for sensitivity, specificity, PPV and NPV of various biochemical parameters.

The cholesterol levels are elevated in exudative pleural effusions of much shorter duration. ${ }^{8}$ The cause of the increased cholesterol concentration in pleural exudates is unknown. Increased pleural permeability leading to accumulation of cholesterol in pleural exudates due to "serum leakage" may be a reasonable explanation. Cholesterol is found in all tissues and is uniformly found in all pleural effusions. ${ }^{9}$

Our results show that an increased concentration of cholesterol greater than $45 \mathrm{mg} / \mathrm{dL}$ in pleural fluid constitute useful measurements for separating exudates from transudates. This finding of our study is also supported by previous study of Heffner JE et al. ${ }^{10}$

In our study we found that in transudative, parapneumonic, tubercular and neoplastic pleural effusions, pleural fluid cholesterol levels with a classifying threshold of $45 \mathrm{mg} / \mathrm{dL}$ has a sensitivity of 98 percent and specificity of 100 percent for diagnosis of exudates with a PPV of $100 \%$.

In the present study when pleural fluid cholesterol cut-off was taken as $60 \mathrm{mg} / \mathrm{dL}$, it was found that the sensitivity of differentiating exudates was $82 \%$, while specificity was found to be $100 \%$ with PPV of $100 \%$ and NPV of $44 \%$. Pleural fluid to serum cholesterol ratio had a sensitivity of $88 \%$ and a specificity of $100 \%$ with PPV of $100 \%$ and NPV of $56 \%$.

Dharmendra A Bamaniya et $\mathrm{al}^{7}$ in his study found that $86.2 \%$ of patients with TB and $79.16 \%$ of malignancy patients had pleural fluid cholesterol levels $>60 \mathrm{mg} / \mathrm{dL}$ with pleural fluid to serum cholesterol ratio of $>0.4$.

Guleria $\mathrm{R}$ et al ${ }^{11}$ investigated the role of pleural fluid cholesterol in differentiating transudative from exudative pleural effusion. Pleural fluid cholesterol had a sensitivity of $88 \%$ and a specificity of $100 \%$ for exudates with an accuracy of $92 \%$ with cut-off value of $60 \mathrm{mg} / \mathrm{dL}$ or above.

Anand $\mathrm{K}$ et $\mathrm{al}^{12}$ in his study using pleural fluid cholesterol levels at a cut-off point of greater than $60 \mathrm{mg} / \mathrm{dL}$ and/or total protein at a cut-off point of greater than $3 \mathrm{mg} / \mathrm{dL}$ for distinguishing transudates and exudates reported the sensitivity, specificity, positive predictive value (PPV) and negative predictive value (NPV) were 100 percent.

$\mathrm{AB}$ Hamal et $\mathrm{al}^{13}$ reported that pleural fluid to serum protein ratio greater than 0.5 has a sensitivity of $81.4 \%$ and specificity of $82.6 \%$; pleural fluid to serum $\mathrm{LDH}$ ratio has a sensitivity of $86 \%$ and specificity of $94.7 \%$ and pleural fluid cholesterol with sensitivity of $97.7 \%$ and specificity of $100 \%$ for differentiating exudative and transudative pleural effusions.

In our study pleural fluid cholesterol criterion correctly classified eight cases of CHF as Transudative effusion, which were misclassified as exudative effusion by Light's criterion. It was most probably due to diuretic therapy frequently given in CHF treatment. In our study it was found that mean value of pleural fluid ADA was 62.33 in tubercular effusion and
24.33 in non-tubercular effusion which is comparable to other studies as shown in Table 3 , hence high levels of ADA is more diagnostic towards tuberculosis. Pleural fluid ADA is a specific and a sensitive marker to differentiate between tuberculous and non-tuberculous pleural effusion and it is becoming popular and a vital tool to differentiate tuberculous from non-tuberculous cases of pleural effusion which is quite handful in countries like India where tuberculosis is prevalent everywhere. ${ }^{7}$

In present study pleural fluid protein $>3 \mathrm{gm} / \mathrm{dL}$ when used as a differentiating parameter for transudates and exudates had a sensitivity of $98 \%$, specificity and PPV of $100 \%$ and NPV of $74 \%$ respectively. Present study is also supported by Anand $\mathrm{K}$ et al ${ }^{12}$ which shows sensitivity of $98 \%$, specificity of $100 \%$, PPV of $100 \%$ and NPV of $92 \%$.

In our study pleural fluid cholesterol and serum cholesterol ratio has sensitivity, specificity, PPV and NPV of $88 \%, 100 \%, 100 \%$ and $56 \%$ respectively with a cut-off $>0.4$.

In the present study pleural fluid LDH to serum LDH ratio has sensitivity, specificity, PPV and NPV of $81 \%, 100 \%, 100 \%$ and $44 \%$ respectively, which was comparable to Lights et al and John Heffner et al.

Pleural fluid LDH level $>2 / 3$ of upper limit of serum LDH reported sensitivity, specificity, PPV and NPV of $82 \%, 100 \%$, $100 \%$ and $46 \%$ respectively, which was comparable to Lights et $\mathrm{al}^{4}$ and John Heffner et $\mathrm{al}^{10}$ study.

Our study also shows that the most common cause of exudative pleural effusion in India is tuberculosis.

\section{CONCLUSION}

The present study entitled "Role of pleural fluid cholesterol in differentiating transudative and exudative pleural effusion" included 204 patients.

\section{The Conclusions of this Study were as follows-}

- Pleural fluid cholesterol is simple, cost effective and useful parameter for differentiation of transudates from exudates with a cut-off level of $45 \mathrm{mg} / \mathrm{dL}$.

- Measurement of pleural fluid total protein also has a good sensitivity and specificity in differentiation of exudative and transudative effusion.

- $\quad$ Our study supports other studies in establishing the vital role and cost effectiveness of these novel biochemical markers (pleural fluid total protein and pleural fluid cholesterol) in comparison to long list of markers in evaluation of pleural effusion, and hence recommends their use.

- Our criteria of using pleural fluid cholesterol to differentiate between exudative and transudative pleural effusion is found to be at par with Light's criteria, which continues to be the most sensitive and specific parameter.

- $\quad$ Pleural fluid cholesterol can be used to correctly classify the type of effusion in case of congestive heart failure with diuretic therapy where light's criteria may be misleading.

- The most common cause of exudative pleural effusion in India is tubercular.

- The mean value of pleural fluid cholesterol in tuberculous, malignant and transudative pleural effusion was found to be $82.7,66.6$ and 27.3 respectively. 
- In present study, mean value of ADA level was 62.33 in tubercular effusion and 24.23 in non-tubercular effusion which is comparable to other studies as shown in Table 3. This suggests that high levels of ADA in pleural fluid is more diagnostic towards tuberculosis.

\section{REFERENCES}

[1] Rahman NM, Munavvar M. Investigation of the patient with pleural effusion. Clin Med (Lond) 2009;9(2):1748.

[2] Seaton A, Seaton D, Leitch AG. Crogtan and Douglas's Respiratory disease. Vol 1. $5^{\text {th }}$ edn. London: Blackwell Science 2000.

[3] Fishman AP, Elias JA, Fishman JA, et al. Fishman's pulmonary disease and disorders. Vol 1 and 2. $4^{\text {th }}$ edn. New York: McGraw-Hill 2008.

[4] Light RW, MacGregor MI, Luchsinger PC, et al. Pleural effusion: the diagnostic separation of transudates and exudates. Ann Intern Med 1972;77(4):507-13.

[5] Sharma SK, Suresh V, Mohan A, et al. A prospective study of sensitivity and specificity of ADA in the diagnosis of tuberculous pleural effusion. The Indian Journal of Chest Disease and Allied Sciences 2001;43(3):149-55.

[6] Sinha PK, Sinha BB, Sinha AR. ADA activity as a diagnostic index of pleural effusion. J Indian Med Assoc 1987;85(1):11-3.
[7] Bamaniya DA, Patel MZ, Kaptan KR. Pleural fluid LDHcholesterol and ADA levels: useful biochemical markers in comparision to Light's criteria for more rapid and accurate evaluation of pleural effusion. Int J Med Sci Public Health 2014;3(7):870-5.

[8] Luetscher JA. Electrophoretic analysis of the proteins of plasma and serous effusion. J Clin Invest 1941;20(1):99-106.

[9] Stein HM. Cholesterol thorax in tuberculosis (Cholesterol pleurisy). Arch Intern Med (Chic) 1932;49(3):421-8.

[10] Heffner JE, Brown LK, Barbieri CA. Diagnostic value of tests that discriminate between exudative and transudative pleural effusions. Chest 1997;111(4):970-80.

[11] Guleria R, Agarwal SR, Sinha S, et al. Role of pleural fluid cholesterol in differentiating transudative from exudative pleural effusion. Natl Med J India 2003;16(2):64-9.

[12] Patel AK, Choudhury S. Combined pleural fluid cholesterol and total protein in differentiation of exudates and transudates. The Indian Journal of Chest Diseases \& Allied Sciences 2013;55(1):21-3.

[13] Hamal AB, Yogi KN, Bam N, et al. Pleural fluid cholesterol in differentiating exudative and transudative pleural effusion. Article ID 135036, Pulmonary Medicine 2013;2013: p. 4. 